\title{
Microvascular Endothelial Dysfunction in Obstructive Sleep Apnea Is Caused by Oxidative Stress and Improved by Continuous Positive Airway Pressure Therapy
}

\author{
Nikolaus J. Büchner ${ }^{a}$ Ivo Quack ${ }^{a, b}$ Magdalena Woznowski ${ }^{a, b}$ \\ Constanze Stähle ${ }^{a} \quad$ Ulrich Wenzel $^{\mathrm{a}}$ Lars C. Rump ${ }^{\mathrm{a}, \mathrm{b}}$

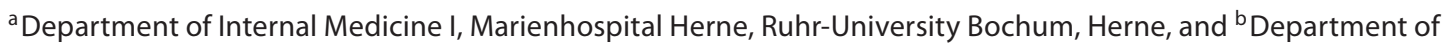 \\ Nephrology, Heinrich Heine University, Düsseldorf, Germany
}

\section{Key Words}

Continuous positive airway pressure $\cdot$ Endothelial dysfunction - Microvascular endothelial function .

Obstructive sleep apnea $\cdot$ Oxidative stress

\begin{abstract}
Background: Endothelial dysfunction has recently been demonstrated in obstructive sleep apnea (OSA), but the underlying mechanisms are not entirely understood. Oxidative stress is a typical feature of OSA. Objectives: We investigated the influence of oxidative stress and continuous positive airway pressure (CPAP) on microvascular endothelial function in OSA. Methods: Endothelial function of forearm resistance vessels was assessed by strain gauge venous occlusion plethysmography after intra-arterial infusion of the endotheliumindependent vasodilator sodium nitroprusside (1.6, 3.2, and $4.0 \mu \mathrm{g} / \mathrm{min}$ ) and the endothelium-dependent vasodilator acetylcholine (Ach, 15, 30 and $40 \mu \mathrm{g} / \mathrm{min}$ ) in patients with ( $n=11$ ) and without $(n=8)$ OSA (apnea-hypopnea index $\geq 15 / h$ ). These measurements have been repeated after local intra-arterial infusion of the antioxidant vitamin C $(25 \mu \mathrm{g} /$ min). Furthermore, 6 patients have been reevaluated after 6 months of OSA treatment. Results: Patients with OSA dem-
\end{abstract}

onstrated impaired endothelial function compared to those without OSA. Thus, related to baseline flow, the increase in forearm blood flow induced by Ach was blunted in patients with OSA (148.7 $\pm 29.7 \%$ in OSA vs. $233.6 \pm 45.7 \%$ in controls, $p=0.001)$. This difference, however, was abolished by co-infusion of vitamin C. Endothelial function markedly improved following treatment in 5 of 6 OSA patients. Conclusions: This study strongly suggests that microvascular endothelial function is affected by OSA predominantly through increased oxidative stress, and treatment of OSA may improve endothelial function mainly by reducing oxidative stress. The role of oxidative stress-induced endothelial dysfunction as a potential promoter of atherosclerosis and an increased cardiovascular risk in patients with OSA should be investigated in further controlled studies.

Copyright $\odot 2011$ S. Karger AG, Basel

\section{Introduction}

Endothelial dysfunction has been demonstrated as an initial and essential step in the development of atherosclerosis [1]. Importantly, endothelial dysfunction proved to be reversible even in the presence of evident athero-

\section{KARGER}

Fax +4161306 1234 E-Mail karger@karger.ch www.karger.com
(C) 2011 S. Karger AG, Basel

0025-7931/11/0825-0409\$38.00/0

Accessible online at:

www.karger.com/res
Nikolaus J. Büchner, MD

Department of Internal Medicine I, Marienhospital Herne

Hölkeskampring 40

DE-44625 Herne (Germany)

Tel. +49 2323499 5110, E-Mail nikolaus.buechner@ rub.de 
sclerotic changes [2]. Therefore, current cardiovascular risk stratification and prevention strategies increasingly focus on endothelial dysfunction as an attractive therapeutic target. While endothelial dysfunction can affect any part of the vasculature, it may cause different clinical manifestations. Thus, in large arteries endothelial dysfunction promotes arterial stiffness and in conductance vessels atherosclerotic plaques are the most important complication. On the other hand, endothelial dysfunction of resistance vessels may directly impair perfusion and hence the function of different organs through vasoconstriction.

Obstructive sleep apnea (OSA) has clearly been linked to increased cardiovascular morbidity and mortality and is highly prevalent in patients with established cardiovascular disease [3-5]. In addition, OSA appeared to increase the risk to develop systemic hypertension independently from other known risk factors [6]. Nonetheless, it remains controversial whether or not OSA serves as an independent cardiovascular risk factor. By all means, treatment of OSA with continuous positive airway pressure (CPAP) resulted in a marked benefit regarding cardiovascular outcome [7], even in patients with mild-to-moderate disease and, remarkably, also in patients without preexisting cardiovascular disease [8].

In this context, blood pressure-lowering effects of OSA treatment by CPAP have been held responsible for the cardiovascular benefits of OSA treatment. Recent meta-analyses, however, documented only modest blood pressure reductions $(1.5-2 \mathrm{~mm} \mathrm{Hg})$ in CPAP-treated OSA patients $[9,10]$. Thus, the marked cardiovascular risk reduction due to CPAP [8] cannot be explained by the reduction in peripheral blood pressure alone and direct vascular impairments through OSA should be considered.

The cardiovascular benefit of OSA treatment may be associated with an improvement in previously impaired endothelial function. However, current evidence about a potential association between OSA and endothelial dysfunction mostly derives from small and inconsistent data sets [11-19] and the mechanisms of impaired vascular function associated with OSA are incompletely understood so far.

Therefore, the present study compared endotheliumdependent and endothelium-independent vasodilatation of resistance vessels in patients with and without OSA and examined the impact of oxidative stress. Additionally, we prospectively investigated the impact of OSA treatment on endothelial function.

\section{Materials and Methods}

\section{Patients}

We prospectively recruited patients with suspected OSA admitted to our sleep clinic through unselected referral. In total, 11 males with confirmation of at least moderate OSA (apnea/hypopnea-index, AHI, $\geq 15 / \mathrm{h}$ ) and 8 patients without OSA have been enrolled in the study. The presence of known cardiovascular risk factors was not an exclusion criterion, but patients with already established atherosclerotic disease (coronary artery disease, peripheral or cerebrovascular disease, myocardial infarction, or stroke) have been excluded from the study as well as those with central sleep apnea, Cheyne-Stokes respiration, hypoventilation syndromes, or periodic limb movement in sleep as the predominant finding. While endothelial function fluctuates during a menstrual cycle [20], females have also been excluded.

\section{Polysomnography}

All patients underwent overnight attended polysomnography as previously described [8]. Apnea was defined as complete cessation of airflow lasting $\geq 10 \mathrm{~s}$, and hypopnea as a $>50 \%$ reduction in respiratory airflow lasting $\geq 10 \mathrm{~s}$ associated with an arousal or oxygen desaturation of $\geq 4 \%$. AHI was calculated as the average number of episodes of apnea and hypopnea per hour of sleep. OSA was diagnosed if AHI was $\geq 5 / \mathrm{h}$ (mild OSA: AHI $\geq 5$ to $<15 / \mathrm{h}$; moderate OSA: AHI 15-30/h; severe OSA: AHI $\geq 30 / \mathrm{h}$ ).

Baseline Data and Definition of Cardiovascular Risk Factors

Standard baseline data included medical history, physical examination, fasting blood screening tests, and electrocardiography. In addition, patients' cardiovascular risk level at baseline was recorded in detail. In all patients, office blood pressure was measured in a sitting position after a rest of at least $5 \mathrm{~min}$. Glucose metabolism was assessed by a 75-gram glucose tolerance test according to the criteria of the American Diabetes Association in patients without known diabetes mellitus.

The classification of risk factors was based on the following predefined criteria: arterial hypertension (defined as blood pressure of $\geq 140 / 90 \mathrm{~mm} \mathrm{Hg}$ or use of antihypertensive drugs); diabetes mellitus (diagnosed when subjects were receiving insulin or oral antidiabetics, if fasting glucose was $\geq 7.0 \mathrm{mM}$, or if blood glucose was $\geq 11.1 \mathrm{mM}$ after glucose challenge); hypercholesterolemia (defined as current use of cholesterol-lowering medications or plasma levels $\geq 5.2 \mathrm{mM}$ and/or LDL cholesterol $\geq 3.4 \mathrm{mM}$ in plasma sampled after overnight fasting).

\section{Treatment and Follow-Up}

CPAP treatment was recommended to all patients with OSA. If patients did not tolerate CPAP treatment, therapy was changed to bilevel-positive airway pressure. At the 6-month follow-up, repeated venous occlusion plethysmography and polysomnography were performed in all patients with OSA.

Venous Occlusion Plethysmography

Forearm blood flow (FBF) was measured by strain gauge occlusion plethysmography (Compactus; Gutmann, Eurasburg, Germany). The principle of this technique is that the stretch of a mercury strain gauge correlates to the volume increase in the forearm, which in turn is proportional to FBF. The strain gauge was placed between the proximal and middle third of the forearm,
Büchner/Quack/Woznowski/Stähle/ Wenzel/Rump 
which was positioned horizontal and in a comfortable way to avoid muscle tension during the measurements.

During each measurement, venous return from the forearm was inhibited by rapid inflation of an upper-arm cuff at $40 \mathrm{~mm}$ $\mathrm{Hg}$ for $6 \mathrm{~s}$. An additional cuff placed at the wrist was inflated with suprasystolic pressure to avoid disturbances through hand circulation, which is variable and hence difficult to estimate.

All measurements were started between 9.00 und 10.00 a.m. in a temperature-controlled $\left(21-23^{\circ} \mathrm{C}\right)$ quiet room. A 20-gauge arterial cannula $(1.1 \times 48 \mathrm{~mm})$ has been placed in the brachial artery of the non-dominant arm of each subject under sterile conditions followed by at least $20 \mathrm{~min}$ of supine rest. Serial infusions were made into the brachial circulation via the arterial cannula using a syringe pump (Perfusor compact; Braun, Melsungen, Germany). The following substances have been infused according the protocol, which is illustrated in figure 1: acetylcholine (Ach; a vasodilator that stimulates the release of nitric oxide and other vasodilator substances from the endothelium), sodium nitroprusside (SNP; an endothelium-independent vasodilator), and vitamin $\mathrm{C}$ (a known antioxidant, co-infused with Ach).

Subjects were asked to avoid smoking, heavy exercise, and drinking alcohol or caffeinated beverages for at least $2 \mathrm{~h}$ prior to examination. All patients continued their usual medications.

FBF was expressed in milliliters per minute per $100 \mathrm{ml}$ of forearm volume. Changes in blood flow were reported as percentage changes from baseline flow and from maximal flow achieved by the endothelium-independent vasodilator SNP.

\section{Protocol}

After a supine rest of at least $20 \mathrm{~min}, 0.9 \%$ saline was infused into the intra-arterial cannula for $15 \mathrm{~min}$ ( $1 \mathrm{ml}$ per min) and baseline FBF was measured ( 3 automatic measurements after 13, 14, and $15 \mathrm{~min}$ ). Subsequently, Ach (Clinalfa, Läufelfingen, Switzerland) was infused at ascending doses $(15,30$, and $40 \mu \mathrm{g} / \mathrm{min})$ for $5 \mathrm{~min}$, respectively. FBF measurements were repeated after 3 , 4 , and $5 \mathrm{~min}$ for each dose. After a 30-min washout period with $0.9 \%$ saline, these measurements were repeated after Ach infusion and co-infusion of vitamin C (25 $\mathrm{g} / \mathrm{min}$; Wörwag Pharma, Böblingen, Germany), which started $10 \mathrm{~min}$ before Ach infusion. After another 30-min washout period, 5-min infusions of SNP (Schwarz Pharma, Monheim, Germany) were given at doses of $1.6,3.2$, and $4.0 \mu \mathrm{g} / \mathrm{min}$, respectively. The mean of three measurements at each dose was calculated and used for further statistical analyses.

The sequence of the application of the drugs used is illustrated in figure 1.

\section{Follow-Up Investigations}

A follow-up polysomnography and measurement of endothelial function by venous occlusive plethysmography was intended after 6 months in all OSA patients. Compliance was defined as use CPAP for $\geq 4$ h per night on average. OSA treatment was considered effective if the patient was compliant with CPAP (daily usage of $\geq 4 \mathrm{~h}$ on average) and AHI was both reduced by $\geq 50 \%$ and below $10 /$ h.

\section{Analysis}

Statistical analyses were performed with the computer software SPSS for Windows (version 11.5.1; SPSS, Chicago, Ill., USA).

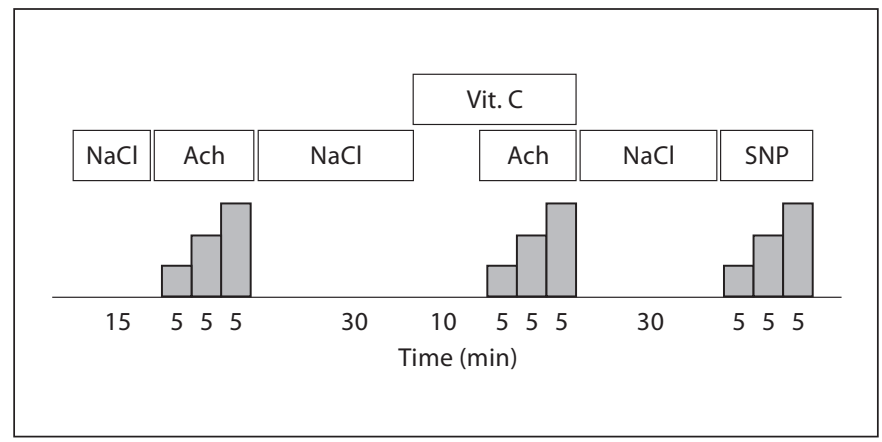

Fig. 1. Infusion protocol for all vascular studies. $\mathrm{NaCl}$ : $0.9 \%$ saline; Ach: 15, 30, and $40 \mu \mathrm{g} / \mathrm{min}$, SNP: $1.6,3.2$, and $4.0 \mu \mathrm{g} / \mathrm{min}$, and vitamin $\mathrm{C}$ (Vit. C; $25 \mathrm{mg} / \mathrm{min}$ ). Infusion rate for each substance was $1 \mathrm{ml} / \mathrm{min}$.

Results are given as means $\pm \mathrm{SD}$. All p values reported are two tailed; $p<0.05$ was considered statistically significant. Intergroup differences were analyzed for significant differences with $\chi^{2}$, Student's t test, Mann-Whitney U test, or Wilcoxon rank-sum test, as appropriate.

The relationship between OSA and endothelial function was first explored by bivariate regression analysis. Subsequently, a multivariate linear regression model was established to determine an independent effect of OSA on endothelial function. Parameters of OSA were separately introduced into the model to avoid their unintended statistical interaction. Further parameters included into this model were age, body mass index (BMI), hypertension, diabetes mellitus, and hyperlipidemia.

Written informed consent was obtained from all patients prior to each vascular measurement. The study protocol has been approved by the local ethics committee.

\section{Results}

\section{General Results}

Two patients had moderate and 9 had severe OSA. In 8 additional patients, a significant sleep-related breathing disorder was excluded. Clinical characteristics of the patients with and without OSA are listed in table 1. Briefly, there was a trend towards higher BMI in OSA patients, but there were no significant differences regarding cardiovascular risk factors and co-medication.

In 6 of 11 patients, measurement of endothelial function was repeated after 6 months. Two OSA patients did not attend follow-up investigations and 3 patients declined a repetition of venous occlusion plethysmography. CPAP effectively improved daytime symptoms and nighttime oxygen saturation, and markedly reduced respiratory events in all patients with OSA (table 2). 


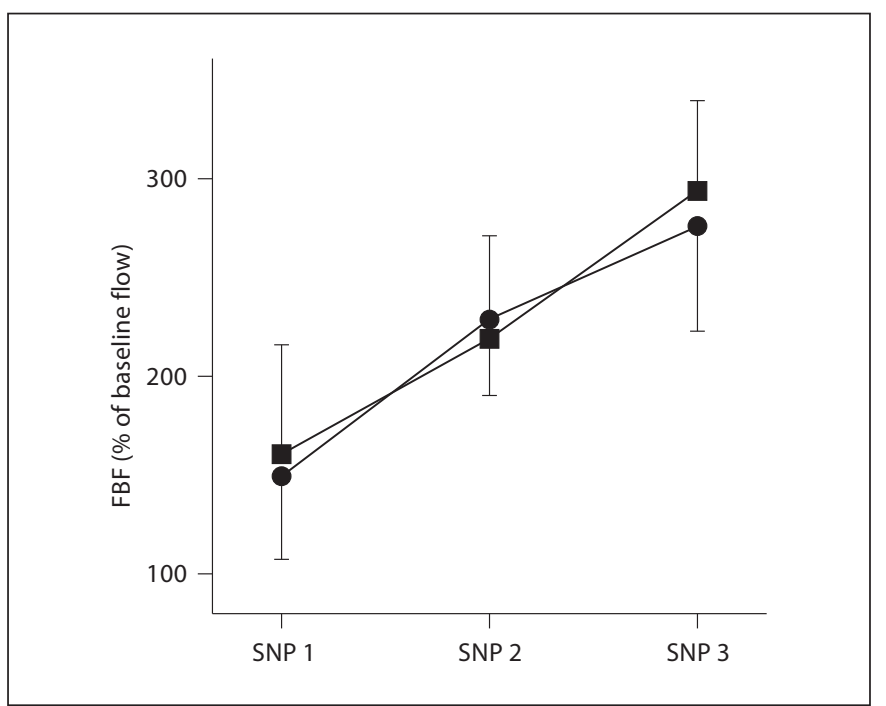

Fig. 2. FBF increase following SNP infusion in ascending doses $(\mathrm{SNP} 1=1.6 \mu \mathrm{g} / \mathrm{min}, \mathrm{SNP} 2=3.2 \mu \mathrm{g} / \mathrm{min}$, and SNP $3=4.0 \mu \mathrm{g} /$ $\mathrm{min})$ related to baseline FBF. Means $\pm \mathrm{SD}$. $\mathbf{\square}=$ Controls; $\bullet=$ OSA patients. No significant difference was found.

\section{Endothelial Function}

FBF at baseline $(2.79 \pm 0.34$ vs. $2.52 \pm 0.38 \mathrm{ml} / 100$ $\mathrm{ml} / \mathrm{min}$, nonsignificant) and endothelium-independent vasodilatation by intra-arterial infusion of SNP (7.7 \pm 1.8 vs. $7.8 \pm 0.8 \mathrm{ml} / 100 \mathrm{ml} / \mathrm{min}$, nonsignificant; fig. 2 ) were not significantly different between OSA patients and controls.

Intra-arterial infusion of Ach in ascending doses resulted in increased FBF in all measurements, with a maximum at $40 \mu \mathrm{g} / \mathrm{min}$. However, this increase was blunted in patients with OSA compared to controls (fig. 3). Related to baseline FBF, the maximal increase induced by Ach was $148.7 \pm 29.7 \%$ in OSA patients and $233.6 \pm$ $45.7 \%$ in controls $(\mathrm{p}=0.001)$. Related to maximum blood flow by SNP, the FBF increase caused by $40 \mu \mathrm{g} / \mathrm{min}$ Ach was $16.0 \pm 11.9$ percentage points in patients with OSA and $44.8 \pm 12.2$ percentage points in controls $(\mathrm{p}<0.001)$.

In the whole study group, endothelial function (assessed by Ach-induced changes in FBF related to baseline FBF) was strongly associated with AHI $(r=-0.681$, $p=0.001)$, mean oxygen saturation $(r=0.516, p=0.024)$, and age $(\mathrm{r}=-0.520, \mathrm{p}=0.022)$. No correlations were found between endothelium-dependent vasodilatation and time spent with oxygen saturation $<90 \%, \mathrm{BMI}$, and the presence of hypertension, diabetes mellitus, and hyperlipidemia. In multivariate analyses (multiple logistic regression) including AHI, mean oxygen saturation, age,
Table 1. Clinical and polysomnographic characteristics of patients with OSA and controls without OSA

\begin{tabular}{llll}
\hline Characteristics & $\begin{array}{l}\text { OSA } \\
(\mathrm{n}=11)\end{array}$ & $\begin{array}{l}\text { No OSA } \\
(\mathrm{n}=8)\end{array}$ & p value \\
\hline Age, years & $50.5 \pm 6.9$ & $44.5 \pm 10.5$ & $\mathrm{NS}$ \\
$\mathrm{BMI}$ & $30.1 \pm 6.6$ & $25.6 \pm 2.9$ & $\mathrm{NS}(0.061)$ \\
$\mathrm{AHI}, \mathrm{n} / \mathrm{h}$ & $42.4 \pm 20.2$ & $1.4 \pm 1.5$ & $<0.001$ \\
$\mathrm{t}_{90}, \%$ & $26.5 \pm 34.8$ & $0.3 \pm 0.5$ & $<0.001$ \\
Minimal SO $_{2}, \%$ & $81.1 \pm 6.2$ & $91.1 \pm 1.8$ & $<0.001$ \\
${\text { Mean } \mathrm{SO}_{2}, \%}^{\text {Hypertension }}$ & $90.8 \pm 2.9$ & $95.6 \pm 1.1$ & $<0.001$ \\
Diabetes mellitus & $6(54.4 \%)$ & $3(37.5 \%)$ & $\mathrm{NS}$ \\
Hyperlipidemia & $2(18.2 \%)$ & $1(12.5 \%)$ & $\mathrm{NS}$ \\
Antihypertensive drugs & $2(18.2 \%)$ & $1(12.5 \%)$ & $\mathrm{NS}$ \\
Lipid-lowering drugs & $2(18.5 \%)$ & $2(25.0 \%)$ & $\mathrm{NS}$ \\
& & $1(12.5 \%)$ & $\mathrm{NS}$
\end{tabular}

$t_{90}=$ Percentage of the night spent with oxygen saturation $\left(\mathrm{SO}_{2}\right)<90 \%$.

Table 2. Polysomnographic data in patients before and after 6 months of OSA treatment $(n=6)$

\begin{tabular}{llcl}
\hline Parameters & Baseline & After CPAP & p value \\
\hline $\mathrm{AHI}, \mathrm{n} / \mathrm{h}$ & $37.9 \pm 26.1$ & $1.0 \pm 1.6$ & 0.010 \\
$\mathrm{t}_{90}$ & $27.8 \pm 37.9$ & $1.4 \pm 1.6$ & $\mathrm{NS}$ \\
Minimal SO$_{2}, \%$ & $80.2 \pm 8.2$ & $89.0 \pm 1.4$ & $\mathrm{NS}(0.051)$ \\
$\mathrm{Mean} \mathrm{SO}_{2}, \%$ & $90.2 \pm 3.4$ & $93.8 \pm 1.2$ & 0.045
\end{tabular}

$\mathrm{t}_{90}=$ Percentage of the night spent with oxygen saturation $\left(\mathrm{SO}_{2}\right)<90 \%$.

BMI, hypertension, diabetes mellitus, and hyperlipidemia, the influence of AHI $(\beta=-1.053, p=0.003)$ and age $(\beta=-0.521, p=0.021)$ proved to be independent from the other covariates mentioned.

\section{Oxidative Stress}

Only in OSA patients intra-arterial co-infusion of the antioxidant vitamin $\mathrm{C}$ resulted in a sharper increase in FBF induced by acetylcholine in ascending doses, whereas vitamin $\mathrm{C}$ did not further increase FBF during intraarterial infusion of Ach in controls (fig. 4). The FBF increase with vitamin $\mathrm{C}$ and Ach in OSA patients reached levels that were not significantly different from those of controls treated with the vitamin C-Ach combination, or Ach alone (fig. 4). 

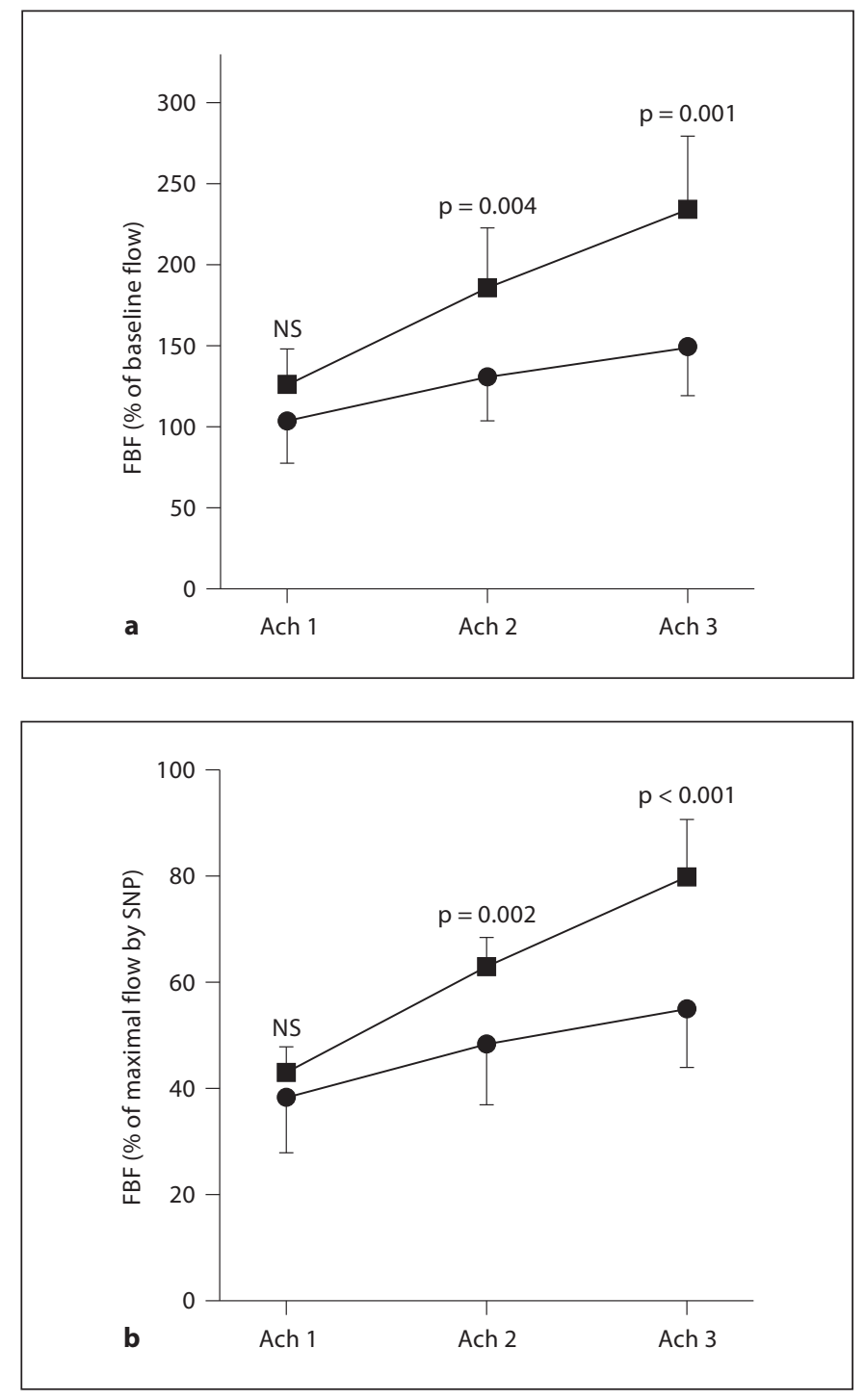

Fig. 3. FBF increase following Ach in ascending doses (Ach $1=$ $15 \mu \mathrm{g} / \mathrm{min}$, Ach $2=30 \mu \mathrm{g} / \mathrm{min}$, and Ach $3=40 \mu \mathrm{g} / \mathrm{min}$ ) related to baseline FBF (a) and maximal flow by intra-arterial infusion of SNP (b). Means \pm SD. $\mathbf{a}=$ Controls; 0 OSA patients

\section{Impact of OSA Treatment on Endothelium-Dependent Vasodilatation}

In 5 of 6 patients, OSA treatment resulted in a marked improvement in endothelium-dependent vasodilatation (fig. 5). After 6 months of CPAP, there was an increase in Ach-induced FBF related to baseline blood flow and maximal blood flow by SNP $(57.1 \pm 13.9 \%$ before and $67.2 \pm$ $14.9 \%$ after CPAP, nonsignificant) that reached baseline levels of controls. Co-infusion with vitamin $\mathrm{C}$ did not further increase FBF (FBF increase related to maximal

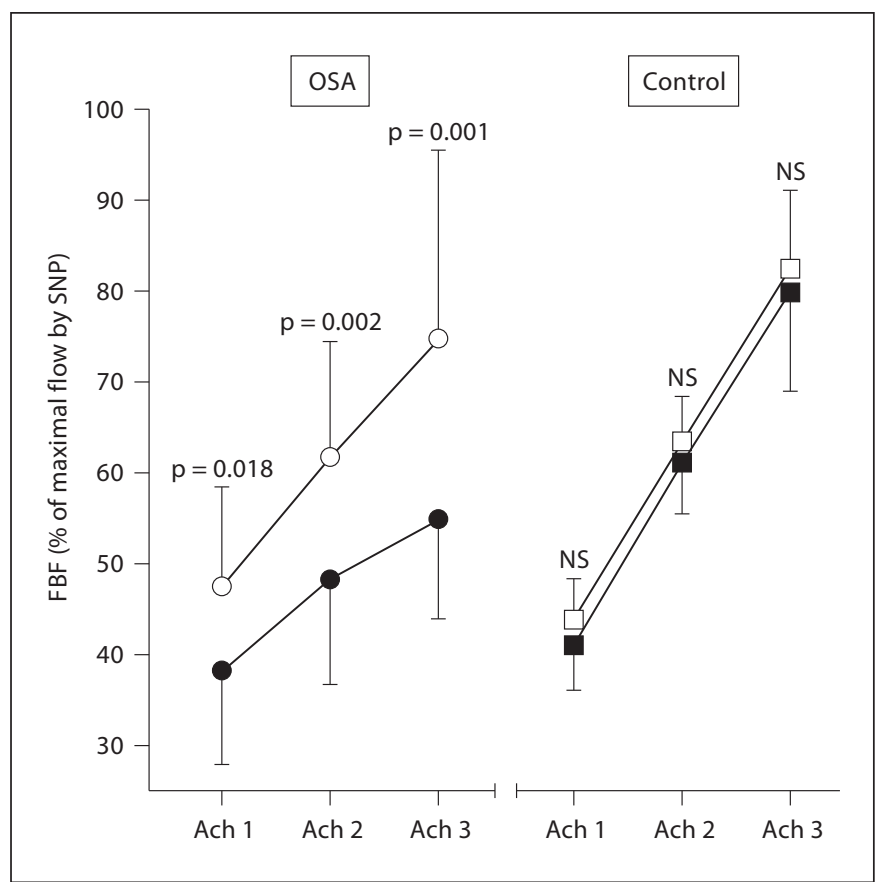

Fig. 4. FBF increase following Ach infusion in ascending doses (Ach $1=15 \mu \mathrm{g} / \mathrm{min}$, Ach $2=30 \mu \mathrm{g} / \mathrm{min}$, and Ach $3=40 \mu \mathrm{g} / \mathrm{min}$ ) related to maximal flow by intra-arterial infusion of SNP. Means \pm SD. $\square, \square=$ Controls; $\square, O=$ OSA patients; $\square, \bullet=$ intra-arterial infusion of Ach alone; $\square, \bigcirc=$ intra-arterial infusion of Ach and vitamin C (25 mg/min). Only in OSA patients co-infused with vitamin $\mathrm{C} \mathrm{FBF}$ increased compared to maximal flow by SNP (from $54.8 \pm 10.9$ to $74.7 \pm 20.8 \%, \mathrm{p}=0.001$ ).

blood flow by SNP: Ach: $67.2 \pm 14.9 \%$, Ach + vitamin C: $66.8 \pm 20.9 \%$, nonsignificant). Endothelium-independent vasodilatation through intra-arterially infused SNP was not significantly changed in the course of OSA treatment (maximal FBF with SNP related to baseline blood flow before CPAP: $279.9 \pm 40.5 \%$ and after 6 months of CPAP: $287.8 \pm 89.5 \%$, nonsignificant).

\section{Discussion}

The present controlled study yielded three major findings. (1) OSA impairs microvascular endothelial function independently of age and classical cardiovascular risk factors. The degree of endothelial dysfunction is associated with the severity of OSA assessed by AHI. (2) As a new finding, intra-arterial infusion of the antioxidant vitamin C acutely improves endothelial dysfunction of forearm resistance vessels to levels of controls, suggesting 

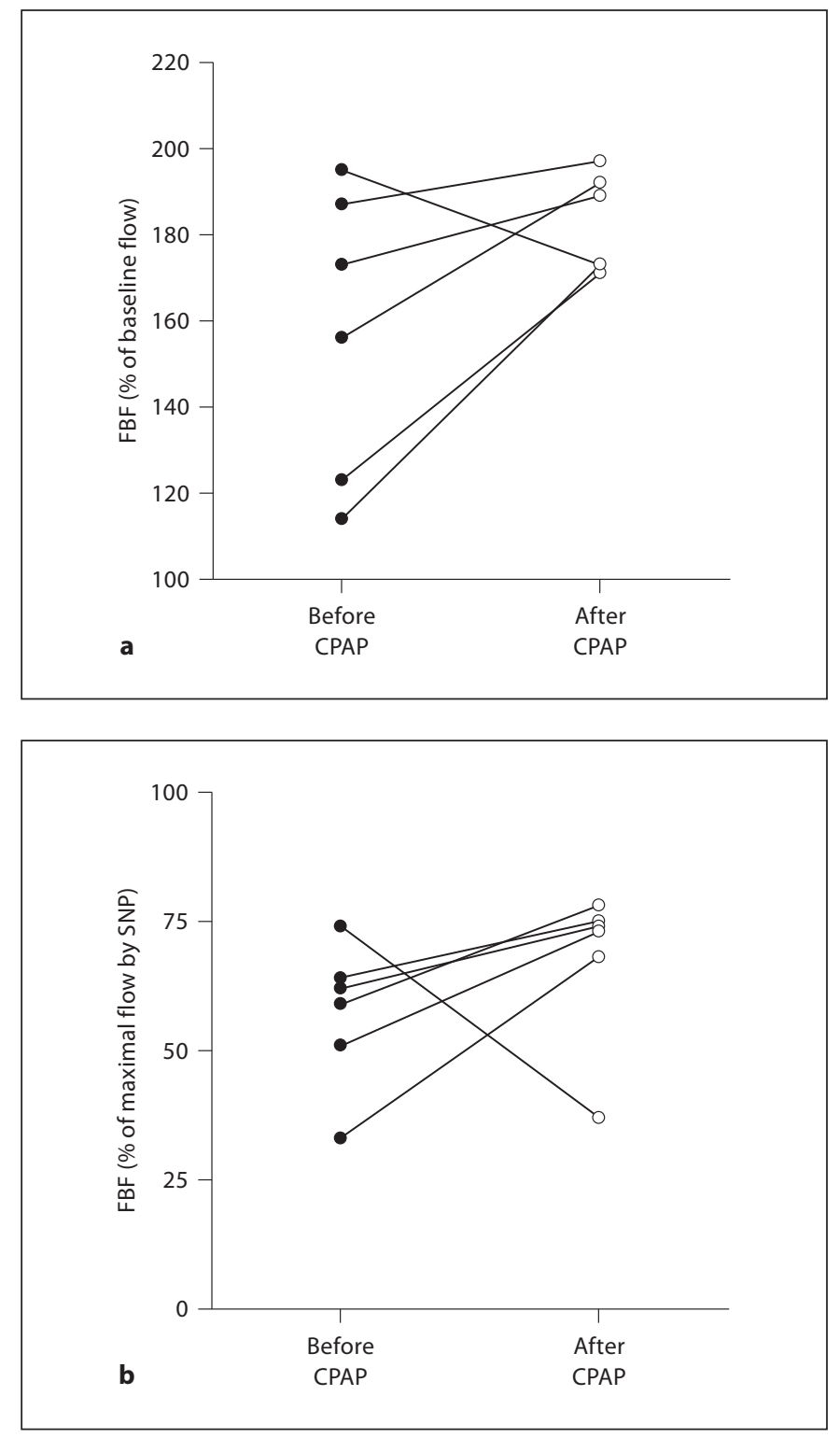

Fig. 5. Increase in FBF following Ach infusion ( $40 \mu \mathrm{g} / \mathrm{min}) \mathrm{re}-$ lated to baseline (a) and maximal (b) flow by intra-arterial infusion of SNP. $\bullet=$ Before CPAP; $\bigcirc=$ after CPAP.

that endothelial dysfunction of the microvasculature in OSA is predominantly caused by oxidative stress. (3) Although not statistically significant, this study strongly favors an improvement in endothelial function by CPAP, most likely caused by a reduction in oxidative stress.

OSA is strongly associated with an increased cardiovascular risk, which can be reduced or even normalized by OSA treatment $[7,8]$, whereas the mechanisms of this effect are not entirely understood. Several studies ad- dressed endothelial dysfunction as a potential trigger of atherosclerosis and hence of the cardiovascular burden in OSA. The evidence of a correlation between OSA and endothelial dysfunction, however, remains inconsistent in these studies. Thus, some studies found reduced flowmediated vasodilatation, a method to assess the endothelial function of conductance vessels (mostly the brachial artery) in OSA patients [14, 17, 19,21, 22], which was not confirmed by another study [16]. In addition, Chami et al. [18] recently failed to demonstrate a link between sleep-disordered breathing and brachial artery flow-mediated dilation in a large community-based, cross-sectional observational study with 327 men and 355 women from the Framingham Heart Study site of the Sleep Heart Health Study. Faulx et al. [23] demonstrated a correlation between AHI and flow-mediated dilatation only in women but not in men. Using venous occlusive plethysmography, which also includes resistance vessels, small studies found an impairment in endothelial function $[13,15]$ even in otherwise healthy patients with OSA [16]. On the other hand, Kraiczi et al. [24] could not confirm these results after correction for different covariates but reported increased vasoconstrictor sensitivity in the forearm vasculature of OSA patients instead.

Endothelial dysfunction is thought to be the link between different cardiovascular risk factors and atherosclerosis as their uniform clinical expression. Therefore, the known high prevalence of classical cardiovascular risk factors in OSA might cover a potentially independent association between OSA and endothelial dysfunction, especially if the sample size of a study is small, as it is in the present study. Some authors addressed this problem by excluding OSA patients with other cardiovascular risk factors. These results, however, are not applicable to the typical cohort of OSA patients, which in fact is characterized by a high prevalence of classical cardiovascular risk factors.

In the present study, we therefore excluded patients with apparent atherosclerosis but not those with known hypertension, diabetes mellitus, hyperlipidemia, and obesity. However, there were no significant differences in cardiovascular risk factors between OSA patients and controls. Furthermore, in multivariate analyses, AHI, a marker of OSA severity, predicted endothelial dysfunction independently of various covariates. An independent association of OSA severity and other markers of endothelial function (flow-mediated vasodilatation [25], circulating NO and its metabolites [26], or carotis intimamedia thickness [27]) has been reported previously as 
well. In line with these results, our study therefore supports an independent influence of OSA severity on endothelial function.

In the present study, intra-arterial infusion of the antioxidant vitamin $\mathrm{C}$ markedly improved or even normalized daytime endothelial function in OSA patients, whereas no such changes were seen in controls. Oxidative stress is a known feature of OSA [28], which is thought to be mainly caused by intermittent hypoxia/ reoxygenation.

In OSA patients, Grebe et al. [29] found endothelial dysfunction of conductance vessels improved by systemic intravenous application of $0.5 \mathrm{~g}$ of vitamin $\mathrm{C}$, which serves as a scavenger. The present study firstly demonstrates that endothelial dysfunction of the forearm microvasculature is also markedly improved by antioxidant strategies, suggesting that endothelial dysfunction in OSA patients is predominantly induced by oxidative stress. However, after 6 months of CPAP there was no improvement in endothelial function by vitamin C, suggesting that increased oxidative stress has been sufficiently controlled by CPAP. CPAP has previously been shown to reduce or even eliminate the OSA-associated increase in ROS [28].

Oxidative stress in OSA might also be promoted by the renin-angiotensin-aldosterone-system (RAAS). Among others, angiotensin-converting-enzyme (ACE) is produced in endothelial cells. Its production and activity is increased by shear stress. ACE in turn increases angiotensin II, which is known to increase oxidative stress. Additionally, ACE inactivates the vasodilator bradykinin. Repetitive changes in central blood volume are a typical feature of OSA and could therefore promote shear stress and hence oxidative stress. An increased RAAS activity was also found in OSA [30] and OSA treatment reduced angiotensin II and aldosterone [30]. Therefore OSA might cause endothelial dysfunction via increased RAAS activity.

Ryan et al. [31] noted selective activation of the proinflammatory transcription factor NF- $\kappa \mathrm{B}$ in HeLa cells exposed to intermitted hypoxia/reoxygenation as an important molecular mechanism of the initiation of cardiovascular disease. In addition, Yuan et al. [32] reported that intermittent hypoxia induces hypoxia-inducible factor 1 transcriptional activity via a novel signaling pathway involving $\mathrm{Ca}^{2+} /$ calmodulin-dependent kinase. These changes increase the production of hypoxia-sensitive gene products such as endothelin, adrenomedullin, and VEGF [33-35] and pro-inflammatory substances (adhesion molecules, TNF- $\alpha$, and IL-6) $[36,37]$.

Endothelial Dysfunction in Obstructive Sleep Apnea
Furthermore, hypoxia has been shown to reduce the expression of endothelial nitric oxide synthase [38], and biosynthesis of nitric oxide from L-arginine is an oxygendependent process.

Thus, besides promoting oxidative stress, OSA-associated hypoxia can directly impair endothelial function. This hypothesis is supported by Cross et al. [12], who found decreased vascular function in OSA patients with $>20$ desaturations per hour compared to those with $\leq 19$.

Finally, oxidative stress and impaired endothelial function were reported to be classical cardiovascular risk factors in all studies. However, at least in hypertension, it is not clear if endothelial dysfunction is a cause or symptom of hypertension. Interestingly, endothelial dysfunction was found even in normotensive men with a familial history of hypertension [39]. Classical cardiovascular risk factors in turn are frequently encountered in OSA patients and are therefore likely to further affect endothelial function in OSA.

\section{Limitations}

Our study has limitations that need to be taken into consideration. Due to the multifaceted study protocol, we investigated only a small sample of OSA patients and controls. Statistical comparisons and analyses of such small samples certainly have to be considered with caution. However, our results agree with previous studies with similar sample sizes.

To avoid a possible effect of the menstrual cycle on endothelial function [20], women were excluded from the study. Therefore, our results may not be transferable to females.

Ach- and flow-mediated vasodilatation decreases with age [40]. Although not statistically significant, we cannot exclude a certain effect by the slightly higher age in the group of OSA patients.

\section{Conclusion}

The present results suggest that OSA impairs endothelial function of resistance vessels independently from various covariates. For the first time, we could show that endothelial dysfunction of the forearm microvasculature is predominantly caused by oxidative stress, which is a known and typical feature of OSA. In OSA-treated patients, endothelial function markedly improved and did not differ from that of controls without OSA. The antioxidant vitamin $\mathrm{C}$ could not further improve endothelial 
function in OSA-treated patients, suggesting that OSA treatment corrects endothelial dysfunction mostly by reducing oxidative stress. Further studies are needed to investigate the role of oxidative stress-induced endothelial dysfunction as a promoter of atherosclerosis and an increased cardiovascular risk in patients with OSA.

\section{Acknowledgments}

We especially thank T. Holland Letz (Department of Medical Informatics, Biometry and Epidemiology, Ruhr University, Bochum, Germany) for his qualified help with the statistics.

\section{References}

$\checkmark 1$ Bonetti PO, Lerman LO, Lerman A: Endothelial dysfunction: a marker of atherosclerotic risk. Arterioscler Thromb Vasc Biol 2003;23:168-175.

$\checkmark 2$ Cooke JP, Singer AH, Tsao P, Zera P, Rowan RA, Billingham ME: Antiatherogenic effects of L-arginine in the hypercholesterolemic rabbit. J Clin Invest 1992;90:1168-1172.

$\checkmark 3$ Shahar E, Whitney CW, Redline S, Lee ET, Newman AB, Javier Nieto F, O'Connor GT, Boland LL, Schwartz JE, Samet JM: Sleepdisordered breathing and cardiovascular disease: cross-sectional results of the sleep heart health study. Am J Respir Crit Care Med 2001;163:19-25.

4 Peker Y, Hedner J, Norum J, Kraiczi H, Carlson J: Increased incidence of cardiovascular disease in middle-aged men with obstructive sleep apnea: a 7-year follow-up. Am J Respir Crit Care Med 2002;166:159-165.

5 Young T, Finn L, Peppard PE, Szklo-Coxe M, Austin D, Nieto FJ, Stubbs R, Hla KM: Sleep disordered breathing and mortality: eighteen-year follow-up of the Wisconsin sleep cohort. Sleep 2008;31:1071-1078.

6 Peppard PE, Young T, Palta M, Skatrud J: Prospective study of the association between sleep-disordered breathing and hypertension. N Engl J Med 2000;342:1378-1384.

7 Marin JM, Carrizo SJ, Vicente E, Agusti AG: Long-term cardiovascular outcomes in men with obstructive sleep apnoea-hypopnoea with or without treatment with continuous positive airway pressure: An observational study. Lancet 2005;365:1046-1053.

-8 Buchner NJ, Sanner BM, Borgel J, Rump LC: Continuous positive airway pressure treatment of mild to moderate obstructive sleep apnea reduces cardiovascular risk. Am J Respir Crit Care Med 2007;176:1274-1280.

$\checkmark 9$ Haentjens P, Van Meerhaeghe A, Moscariello A, De Weerdt S, Poppe K, Dupont A, Velkeniers B: The impact of continuous positive airway pressure on blood pressure in patients with obstructive sleep apnea syndrome: evidence from a meta-analysis of placebo-controlled randomized trials. Arch Intern Med 2007;167:757-764.

10 Bazzano LA, Khan Z, Reynolds K, He J: Effect of nocturnal nasal continuous positive airway pressure on blood pressure in obstructive sleep apnea. Hypertension 2007;50: 417-423.
11 Kraiczi H, Hedner J, Peker Y, Carlson J: Increased vasoconstrictor sensitivity in obstructive sleep apnea. J Appl Physiol 2000;89: 493-498.

12 Cross MD, Mills NL, Al-Abri M, Riha R, Vennelle M, Mackay TW, Newby DE, Douglas NJ: Continuous positive airway pressure improves vascular function in obstructive sleep apnoea/hypopnoea syndrome: a randomised controlled trial. Thorax 2008;63: 578-583.

13 Imadojemu VA, Gleeson K, Quraishi SA, Kunselman AR, Sinoway LI, Leuenberger UA: Impaired vasodilator responses in obstructive sleep apnea are improved with continuous positive airway pressure therapy. Am J Respir Crit Care Med 2002;165:950953.

14 Kohler M, Craig S, Nicoll D, Leeson P, Davies RJ, Stradling JR: Endothelial function and arterial stiffness in minimally symptomatic obstructive sleep apnea. Am J Respir Crit Care Med 2008;178:984-988.

15 Carlson JT, Rangemark C, Hedner JA: Attenuated endothelium-dependent vascular relaxation in patients with sleep apnoea. J Hypertens 1996;14:577-584.

16 Kato M, Roberts-Thomson P, Phillips BG, Haynes WG, Winnicki M, Accurso V, Somers VK: Impairment of endothelium-dependent vasodilation of resistance vessels in patients with obstructive sleep apnea. Circulation 2000;102:2607-2610.

$\checkmark 17$ Bayram NA, Ciftci B, Keles T, Durmaz T, Turhan S, Bozkurt E, Peker Y: Endothelial function in normotensive men with obstructive sleep apnea before and 6 months after CPAP treatment. Sleep 2009;32:1257-1263.

18 Chami HA, Keyes MJ, Vita JA, Mitchell GF, Larson MG, Fan S, Vasan RS, O'Connor GT, Benjamin EJ, Gottlieb DJ: Brachial artery diameter, blood flow and flow-mediated dilation in sleep-disordered breathing. Vasc Med 2009; 14:351-360.

19 Chung S, Yoon IY, Lee CH, Kim JW: The association of nocturnal hypoxemia with arterial stiffness and endothelial dysfunction in male patients with obstructive sleep apnea syndrome. Respiration 2010;79:363-369.
20 Büchner NJ, Rump LC: Oral contraceptives and endothelial function: harm or benefit? J Hypertens 2003;21:2227-2230.

-21 Ip MS, Tse HF, Lam B, Tsang KW, Lam WK: Endothelial function in obstructive sleep apnea and response to treatment. Am J Respir Crit Care Med 2004;169:348-353.

22 Oflaz H, Cuhadaroglu C, Pamukcu B, Meric M, Ece T, Kasikcioglu E, Koylan N: Endothelial function in patients with obstructive sleep apnea syndrome but without hypertension. Respiration 2006;73:751-756.

23 Faulx MD, Larkin EK, Hoit BD, Aylor JE, Wright AT, Redline S: Sex influences endothelial function in sleep-disordered breathing. Sleep 2004;27:1113-1120.

$>24$ Kraiczi H, Caidahl K, Samuelsson A, Peker Y, Hedner J: Impairment of vascular endothelial function and left ventricular filling: association with the severity of apnea-induced hypoxemia during sleep. Chest 2001; 119:1085-1091.

25 Nieto FJ, Herrington DM, Redline S, Benjamin EJ, Robbins JA: Sleep apnea and markers of vascular endothelial function in a large community sample of older adults. Am J Respir Crit Care Med 2004;169:354-360.

$>26$ Ip MS, Lam B, Chan LY, Zheng L, Tsang KW, Fung PC, Lam WK: Circulating nitric oxide is suppressed in obstructive sleep apnea and is reversed by nasal continuous positive airway pressure. Am J Respir Crit Care Med 2000;162:2166-2171.

-27 Drager LF, Bortolotto LA, Lorenzi MC, Figueiredo AC, Krieger EM, Lorenzi-Filho G: Early signs of atherosclerosis in obstructive sleep apnea. Am J Respir Crit Care Med 2005; 172:613-618.

28 Schulz R, Mahmoudi S, Hattar K, Sibelius U, Olschewski H, Mayer K, Seeger W, Grimminger F: Enhanced release of superoxide from polymorphonuclear neutrophils in obstructive sleep apnea. Impact of continuous positive airway pressure therapy. Am J Respir Crit Care Med 2000;162:566-570.

29 Grebe M, Eisele HJ, Weissmann N, Schaefer C, Tillmanns H, Seeger W, Schulz R: Antioxidant vitamin $\mathrm{C}$ improves endothelial function in obstructive sleep apnea. Am J Respir Crit Care Med 2006;173:897-901.
Büchner/Quack/Woznowski/Stähle/ Wenzel/Rump 
-30 Moller DS, Lind P, Strunge B, Pedersen EB: Abnormal vasoactive hormones and 24hour blood pressure in obstructive sleep apnea. Am J Hypertens 2003;16:274-280.

-31 Ryan S, Taylor CT, McNicholas WT: Selective activation of inflammatory pathways by intermittent hypoxia in obstructive sleep apnea syndrome. Circulation 2005;112:26602667.

-32 Yuan G, Nanduri J, Bhasker CR, Semenza GL, Prabhakar NR: $\mathrm{Ca}^{2+} /$ calmodulin $\mathrm{ki}-$ nase-dependent activation of hypoxia inducible factor 1 transcriptional activity in cells subjected to intermittent hypoxia. J Biol Chem 2005;280:4321-4328.

-33 Schulz R, Hummel C, Heinemann S, Seeger W, Grimminger F: Serum levels of vascular endothelial growth factor are elevated in patients with obstructive sleep apnea and severe nighttime hypoxia. Am J Respir Crit Care Med 2002;165:67-70.
34 Schulz R, Flototto C, Jahn A, Eisele HJ, Weissmann N, Seeger W, Rose F: Circulating adrenomedullin in obstructive sleep apnoea. J Sleep Res 2006;15:89-95.

35 Phillips BG, Narkiewicz K, Pesek CA, Haynes WG, Dyken ME, Somers VK: Effects of obstructive sleep apnea on endothelin-1 and blood pressure. J Hypertens 1999;17:6166

36 Chin K, Nakamura T, Shimizu K, Mishima M, Nakamura T, Miyasaka M, Ohi M: Effects of nasal continuous positive airway pressure on soluble cell adhesion molecules in patients with obstructive sleep apnea syndrome. Am J Med 2000;109:562-567.

37 Vgontzas AN, Papanicolaou DA, Bixler EO, Kales A, Tyson K, Chrousos GP: Elevation of plasma cytokines in disorders of excessive daytime sleepiness: role of sleep disturbance and obesity. J Clin Endocrinol Metab 1997; 82:1313-1316.
38 Toporsian M, Govindaraju K, Nagi M, Eidelman D, Thibault G, Ward ME: Downregulation of endothelial nitric oxide synthase in rat aorta after prolonged hypoxia in vivo. Circ Res 2000;86:671-675.

39 Hamburg NM, Charbonneau F, GerhardHerman M, Ganz P, Creager MA: Comparison of endothelial function in young men and women with a family history of premature coronary artery disease. Am J Cardiol 2004;94:783-785.

40 Taddei S, Virdis A, Mattei P, Ghiadoni L, Gennari A, Fasolo CB, Sudano I, Salvetti A: Aging and endothelial function in normotensive subjects and patients with essential hypertension. Circulation 1995;91:19811987. 